\title{
Theoretical evaluation of PAH dication properties ${ }^{\star}$
}

\author{
G. Malloci ${ }^{1,2}$, C. Joblin ${ }^{1}$, and G. Mulas ${ }^{2}$ \\ ${ }^{1}$ Centre d'Étude Spatiale des Rayonnements, CNRS et Université Paul Sabatier Toulouse 3, Observatoire Midi-Pyrénées, \\ 9 avenue du Colonel Roche, 31028 Toulouse Cedex 04, France \\ e-mail: [giuliano.malloci; christine.joblin]@cesr.fr \\ 2 Istituto Nazionale di Astrofisica - Osservatorio Astronomico di Cagliari, Strada n.54, Loc. Poggio dei Pini, \\ 09012 Capoterra (CA), Italy \\ e-mail: [gmalloci;gmulas]@ca.astro.it
}

Received 17 July 2006 / Accepted 25 September 2006

\section{ABSTRACT}

\begin{abstract}
Aims. We present a systematic, theoretical study of 40 polycyclic aromatic hydrocarbon dications $\left(\mathrm{PAHs}^{++}\right)$containing up to 66 carbon atoms.

Methods. We performed our calculations using well-established quantum-chemical techniques in the framework of (i) the density functional theory (DFT) to obtain the electronic ground-state properties and of (ii) the time-dependent DFT (TD-DFT) to evaluate the excited-state properties.

Results. For each $\mathrm{PAH}^{++}$considered, we computed the absolute visible-UV photo-absorption cross-section up to about $30 \mathrm{eV}$. We also evaluated their vibrational properties and compared them to those of the corresponding neutral and singly-ionised species. We estimated the adiabatic and vertical second ionisation energy $\Delta I$ through total energy differences.

Conclusions. The $\Delta I$ values obtained fall in the energy range 8-13 eV, confirming that PAHs could reach the doubly-ionised state in HI regions. The total integrated IR absorption cross-sections show a marked increase upon ionisation, being on the average about two and five times larger for $\mathrm{PAHs}^{++}$than for PAHs ${ }^{+}$and PAHs, respectively. The visible-UV photo-absorption cross-sections for the 0 , +1 and +2 charge-states show comparable features but $\mathrm{PAHs}^{++}$are found to absorb slightly less than their parent neutral and singly ionised species between $\sim 7$ and $\sim 12 \mathrm{eV}$. Combining these pieces of information, we found that PAHs ${ }^{++}$should actually be stabler against photodissociation than PAHs and $\mathrm{PAHs}^{+}$, if dissociation thresholds are nearly unchanged by ionisation.
\end{abstract}

Key words. astrochemistry - molecular data - molecular processes - ISM: molecules - ultraviolet: ISM - infrared: ISM

\section{Introduction}

Several spectroscopic features, observed in absorption or in emission in a large number of interstellar environments, are hypothesised providing strong evidence of the presence of large carbon-based molecules (Ehrenfreund \& Charnley 2000). Among them are the diffuse interstellar bands (DIBs, Herbig 1995; Fulara \& Krelowski 2000), seen in absorption in the visible-UV; the aromatic infrared bands (AIBs, Peeters et al. 2004; Tielens 2005), dominating the near and mid-IR spectrum of many interstellar sources; the extended red emission (ERE, Witt \& Vijh 2004; Witt et al. 2006) and the blue-luminescence (BL, Vijh et al. 2004, 2005a,b), wide emission bands peaking in the red and blue parts of the visible spectrum, respectively; the UV-bump at $\sim 220 \mathrm{~nm}$ and the far-UV rise in the general interstellar extinction curve (Draine 2003; Fitzpatrick 2004).

Based on their spectral properties, their high photostability, and their organic nature, polycyclic aromatic hydrocarbons (PAHs) are believed to be abundant in the interstellar medium (ISM, Puget \& Léger 1989; Allamandola et al. 1989). Isolated gas-phase PAHs absorb efficiently visible-UV radiation and are therefore likely to contribute to the DIBs spectrum (Léger \& d'Hendecourt 1985; van der Zwet \& Allamandola 1985; Crawford et al. 1985) and to the UV-bump and far-UV rise of the extinction curve (Joblin 1992; Joblin et al. 1992). After photon

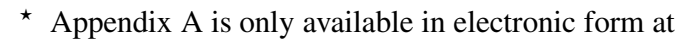
http://www. aanda.org absorption, they undergo a fast radiation-less transition (internal conversion or inter-system crossing) and subsequently relax radiatively by electronic fluorescence and/or phosphorescence (possibly contributing to BL and ERE) and IR emission in their active $\mathrm{C}-\mathrm{C}$ and $\mathrm{C}-\mathrm{H}$ vibrational modes (hence producing AIBs, Léger \& Puget 1984; Allamandola et al. 1985).

Interstellar PAHs are expected to exist in different charge and hydrogenation states depending on the physical conditions of the host environment (Tielens 2005). In particular, the possible presence of PAH dications $\left(\mathrm{PAHs}^{++}\right)$in the ISM, first proposed by Leach (1986), has recently received greater interest, following the proposal that PAHs ${ }^{++}$could be the carriers of ERE (Witt et al. 2006). Theoretical works on the IR properties of a few PAHs ${ }^{++}$(Ellinger et al. 1999; Bauschlicher \& Bakes 2000; Pauzat \& Ellinger 2002) show that their vibrational patterns are similar to those of their parent singly-ionised species $\left(\mathrm{PAHs}^{+}\right)$. From modelling studies, it is predicted that specific values of electron density and radiation field intensity ought to lead to a population of $\mathrm{PAHs}^{++}$in excess of that of $\mathrm{PAHs}^{+}$(Bakes et al. 2001a,b). Therefore PAHs ${ }^{++}$would also contribute to the AIBs.

While the first ionisation energies $I^{+}$for more than 200 PAHs containing up to 48 carbon atoms are well-documented (Eilfeld \& Schmidt 1981), only a few experimental determinations of the double-ionisation energy $I^{++}$of some PAHs have been published to date. Using photon impact, electron impact and, charge stripping techniques, Tobita et al. (1994) made a comprehensive study of $I^{+}$and $I^{++}$for 21 different PAHs up to the size of 
coronene $\left(\mathrm{C}_{24} \mathrm{H}_{12}\right)$. More recently, Schröder et al. (2001) presented a combination between photo-ionisation, charge stripping, reactivity studies, and quantum-chemical calculations to obtain the single and double ionisation energies of corannulene $\left(\mathrm{C}_{20} \mathrm{H}_{10}\right)$ and coronene.

From the known values of $I^{+}$and $I^{++}$, it has been suggested (Leach 1986, 1987, 1989, 1995, 1996) that $\mathrm{PAHs}^{++}$could be formed in diffuse HI regions. The proposed formation mechanism is a sequential two-photon absorption process in which the ionisation of a $\mathrm{PAH}$ is followed by a further ionisation of $\mathrm{PAH}^{+}$. The minimum energy needed for the first step is the single ionisation energy $I^{+}$, while the second step requires a photon energy of at least $\Delta I=I^{++}-I^{+}$; the maximum amount of internal energy in the newly formed $\mathrm{PAHs}^{++}$is therefore $13.6 \mathrm{eV}-\Delta I$. Since the total energy of the dication is larger than the sum of the total energies of two singly ionised fragments, $\mathrm{PAHs}^{++}$are metastable (Rosi et al. 2004) and could be dissociated via Coulomb explosion as shown experimentally (Leach et al. 1989a,b). However, theoretical calculations of the fragmentation pathways of the benzene dication (Rosi et al. 2004) show that this charge separation mechanism should not be a significant channel in most astrophysical environments. This is consistent with the observed production of significant amounts of $\mathrm{PAHs}^{++}$in soft ionisation experiments (Ledingham et al. 1999). Therefore $\mathrm{PAHs}^{++}$could be found in the ISM.

To evaluate the possible contribution of $\mathrm{PAHs}^{++}$to ERE Witt et al. (2006) computed the first low-lying electronic transitions of five representative $\mathrm{PAHs}^{++}$up to the size of ovalene $\left(\mathrm{C}_{32} \mathrm{H}_{14}\right)$, showing that they indeed fall in the spectral range of the observed ERE. Laboratory measurements of the yield of optical fluorescence by $\mathrm{PAHs}^{++}$are, however, needed to test this hypothesis. To the best of our knowledge, with the exception of the work by Witt et al. (2006), no other electronic spectra of PAHs ${ }^{++}$ have been published to date. In particular, a detailed study of the electronic excitation properties for a large sample of $\mathrm{PAHs}^{++}$up to the energies excitable in typical interstellar sources, together with their vibrational analyses, has been missing until now.

In the past few years, we started a long-term project to produce an atlas of synthetic absorption and emission spectra of specific PAHs to be compared with astronomical observations (Joblin et al. 2002; Malloci et al. 2003; Mulas et al. 2003, $2006 a, b, c)$. This requires the use of some key molecular parameters of PAHs as a basis for running Monte-Carlo simulations (Barker 1983; Mulas 1998; Joblin et al. 2002) of their photophysics in the ISM. We report these fundamental data here for a sample of $40 \mathrm{PAHs}^{++}$ranging in size from naphthalene and azulene $\left(\mathrm{C}_{10} \mathrm{H}_{8}\right)$ to circumovalene $\left(\mathrm{C}_{66} \mathrm{H}_{20}\right)$. Even if PAHs and related species containing from less than 50 to more than 200 carbon atoms are expected to be present in the ISM (Boulanger 1999), we restricted ourselves here to species containing up to a maximum of 66 carbon atoms, since computational costs scale steeply with dimensions. Following our previous work on neutral, cationic, and anionic PAHs (Malloci et al. 2004, 2005), we computed the absolute photo-absorption cross-section for the doubly-ionised species. For these same molecules we also evaluated the IR spectral properties, extending the sample of specific $\mathrm{PAH}^{++}$for which they were previously available (Ellinger et al. 1999; Bauschlicher \& Bakes 2000; Pauzat \& Ellinger 2002). New calculations, together with our previous results at the same level of theory for the corresponding PAHs and PAHs ${ }^{+}$, enabled us to estimate, via total energy differences, the adiabatic and vertical $I^{+}$and $I^{++}$. Although the computational approach we used for this purpose is not sufficient to predict absolute ionisation energies with chemical accuracy $( \pm 0.1 \mathrm{eV})$, it reasonably agrees with the available experimental data and can be easily extended to larger PAHs in the near future.

Section 2 contains the technical details for the calculation of the ionisation energies and the vibrational properties (Sect. 2.1) and the photo-absorption spectra (Sect. 2.2). The results obtained are presented in Sect. 3 and discussed in Sect. 4. Our conclusions are reported in Sect. 5.

\section{Computational details}

Due to the large number of electrons in the molecules considered (416 in the largest one, circumovalene), any ab initio study based on the direct solution of the many-electron Schrödinger equation currently has prohibitive computational costs. We used the density functional theory (DFT, Jones \& Gunnarsson 1989) here and its time-dependent extension (TD-DFT, Marques \& Gross 2004), which are the methods of choice for the study, respectively, of the ground-state and the excited-state properties of such complex molecules as PAHs.

\subsection{Ionisation energies and vibrational properties}

Adiabatic single and double ionisation energies (AIEs) are evaluated as the difference between the total energies of the neutral and the corresponding cation and dication in their stablest configurations, respectively. These quantities, therefore, take into account the structural relaxation of the molecule after each ionisation process. The single and double vertical ionisation energies (VIEs), computed at the optimised geometry of the neutral molecule, neglect structural relaxation but include wave-functions relaxation following the removal of one and two electrons.

To estimate AIEs and VIEs, we used the hybrid B3LYP functional, a combination of Becke's three-parameter exchange functional (Becke 1993) and of the Lee-Yang-Parr gradient-corrected correlation functional (Lee et al. 1988). Hybrid DFT functionals are a little more expensive than other exchange-correlation functionals but yield better results. The B3LYP functional, in particular, is widely used in the study of PAHs and related species (Martin et al. 1996; Langhoff 1996; Wiberg 1997; Bauschlicher \& Langhoff 1997; Kato et al. 1999; Kato \& Yamabe 2002; Dessent 2000; Bauschlicher \& Bakes 2000, 2001; Schröder et al. 2001; Rienstra-Kiracofe et al. 2001; Bauschlicher 2002; Parac \& Grimme 2003; Hirata et al. 2003; Deleuze et al. 2003; Rosi et al. 2004; Woon \& Park 2004; Jolibois et al. 2005; Witt et al. 2006; Kadantsev et al. 2006). To assess the impact of this choice we also considered some more recently developed functionals, such as the so-called B-97 (Becke 1997) and HCTH (Hamprecht et al. 1998), but no significant improvements, if any, were obtained with respect to B3LYP for calculating the ionisation energies of PAHs.

For this part of the work we used the Gaussian-based DFT module of the NWCHEM code (Apra et al. 2005). Geometry optimisations were performed using the relatively inexpensive 4-31G basis set, followed by the full vibrational analyses to confirm the geometries obtained to be global minima on the potential energy surface and to evaluate zero-point-energy (ZPE) corrections. In the study of the vibrational properties of PAHs, the combination B3LYP/4-31G was proven to give good results scaling all frequencies by an empirical scale-factor (Langhoff 1996; Bauschlicher \& Langhoff 1997; Bauschlicher \& Bakes 2000, 2001; Bauschlicher 2002). We thus adopted the same scaling procedure derived by these authors to obtain the IR spectra 
of all the PAHs under study in their $0,+1$ and +2 charge states. Since for open-shell systems analytical second derivatives have not yet been implemented in the currently available version of NWCHEM (4.7), we performed the vibrational analyses for all the cations using the GAUSSIAN03 quantum chemistry package (Frisch et al. 2003).

We then started from the optimal geometries and the corresponding self-consistent-field solution obtained in the previous step to refine the optimisation with the $6-31+\mathrm{G}^{\star}$ basis, a valence double zeta set augmented with $d$ polarisation functions and $s$ and $p$ diffuse functions for each carbon atom (Frish et al. 1984). Although basis set convergence is not yet expected at this level, in view of the large systems under study, some compromise between accuracy and computational costs had to be made. Thus, while the B3LYP $/ 6-31+\mathrm{G}^{\star}$ level of theory shows good agreement with experiments for the electron affinities of PAHs (Dessent 2000; Malloci et al. 2005), from previous works (Schröder et al. 2001; Deleuze et al. 2003; Woon \& Park 2004; Kadantsev et al. 2006) it is clear that this same level is certainly unable to predict absolute ionisation energies with chemical accuracy $( \pm 0.1 \mathrm{eV})$. For example, using the 6-311 $\mathrm{g}^{\star \star}$ basis set, Schröder et al. (2001) obtained mean deviations of -0.3 and $-0.8 \mathrm{eV}$ by comparing their computed values for the single and double AIEs of corannulene $\left(\mathrm{C}_{20} \mathrm{H}_{10}\right)$ and coronene $\left(\mathrm{C}_{24} \mathrm{H}_{12}\right)$ with their measured photoionisation thresholds. Analogously, the first AIE of five PAHs in the oligoacenes series from naphthalene to hexacene $\left(\mathrm{C}_{4 n+2} \mathrm{H}_{2 n+4}\right.$ with $n=2$, 3, 4, 5, 6), computed by Kadantsev et al. (2006) using an even larger basis set, underestimate the experimental values by $0.2-0.4 \mathrm{eV}$; the authors concluded that a better description of electron correlation is needed to reproduce experimental IEs.

To estimate the effect of basis set incompleteness, we performed some reference computations for the AIEs of naphthalene $\left(\mathrm{C}_{10} \mathrm{H}_{8}\right)$ and fluorene $\left(\mathrm{C}_{13} \mathrm{H}_{10}\right)$, using the correlation consistent polarised valence basis sets cc-pVDZ and cc-pVTZ (Dunning 1989). These bases have been used in a benchmark-quality study of the ionisation energies of benzene and oligoacenes, to obtain the impressive accuracy of 0.02-0.07 eV (Deleuze et al. 2003). Even if the cc-pVDZ set is less accurate than the $6-31+\mathrm{G}^{*}$ set and the cc-pVTZ is far from complete, this comparison provides us some insight into basis set requirements. As to zero-point-energy corrections, these same authors found that typical values for the PAHs considered are in the range $0.01-0.03$. Our B3LYP/4-31G values were computed to be within the same order of magnitude and were therefore omitted in the evaluation of the IEs, since they are lower than the accuracy of the method used. Although the basis set limit is not reached in Table 1 (e.g., Kadantsev et al. 2006, report $7.88 \mathrm{eV}$ for the first AIE of naphthalene), it is clearly seen that the performance of the $6-31+G^{\star}$ basis is intermediate between those of Dunning's two basis sets. We thus expect our theoretical predictions to systematically underestimate single and double AIEs roughly by 4 and $5 \%$, respectively, which is sufficiently accurate for the purposes of this work.

The optimised ground-state structures were all planar, with the exception of acenaphthene, fluorene and corannulene. Whenever possible, molecular symmetry was assumed during the calculations. In the case of the more symmetric molecules considered, symmetry breaking was observed upon single and double ionisation, as expected from Jahn-Teller distortion (Torii 1999; Kato et al. 1999). More specifically, we obtained a symmetry reduction from $D_{6 h}$ to $D_{2 h}$ for coronene, circumcoronene and hexabenzocoronene, from $D_{3 h}$ to $C_{2 v}$ for triphenylene and from $D_{5 v}$ to $C_{s}$ for corannulene. The complete set of the
Table 1. Effect of basis set incompleteness on the evaluation of single and double AIEs of naphthalene and fluorene at the B3LYP level of theory, the reported values (in $\mathrm{eV}$ ) do not include $\mathrm{ZPE}$ corrections.

\begin{tabular}{ccccc}
\hline \hline Basis & \multicolumn{2}{c}{ Naphthalene $\left(\mathrm{C}_{10} \mathrm{H}_{8}\right)$} & \multicolumn{2}{c}{ Fluorene } \\
set & single IE & double IE & single IE & double IE \\
\hline $4-31 \mathrm{G}$ & 7.61 & 20.75 & 7.38 & 19.72 \\
$6-31+\mathrm{G}^{\star}$ & $7.80^{a, b}$ & $20.99^{b}$ & 7.56 & 19.96 \\
cc-pVDZ & $7.75^{c}$ & 20.95 & 7.51 & 19.89 \\
cc-pVTZ & $7.85^{c}$ & 21.09 & 7.61 & 20.04 \\
\hline Exp. & $8.144 \pm 0.001^{d}$ & $21.5 \pm 0.2^{e}$ & $7.91 \pm 0.02^{d}$ & $21.0 \pm 0.2^{e}$ \\
\hline
\end{tabular}

${ }^{a}$ The use of the $6-31+\mathrm{G}^{\star \star}$ basis set (including polarisation functions on both $\mathrm{C}$ and $\mathrm{H}$ atoms) leads to the same value (Woon \& Park 2004). ${ }^{b}$ Using the $6-311 \mathrm{G}^{\star \star}$ basis set (which is supplemented with a third layer of valence functions and includes polarisation functions) Schröder et al. (2001) obtain 7.82 and 21.04, respectively.

${ }^{c}$ At the same level, Deleuze et al. (2003) report 7.75 and $7.83 \mathrm{eV}$.

${ }^{d}$ Recommended values (NIST Chemistry WebBook, Lias 2005).

${ }^{e}$ Derived from photon impact experiments (Tobita et al. 1994).

40 molecules considered and their symmetry point groups are reported in Table 2 .

\subsection{The real-time TD-DFT method applied to $P A \mathrm{Hs}^{++}$}

The TD-DFT calculations were shown to be a powerful tool for calculating electronic excitation properties for neutral PAHs (Heinze et al. 2000; Parac \& Grimme 2003; Kadantsev et al. 2006) as well as for radical ions up to large species (Hirata et al. 1999, 2003; Halasinski et al. 2000; Halasinski et al. 2003; Weisman et al. 2001, 2003, 2005; Witt et al. 2006). In our previous studies (Malloci et al. 2004, 2005), we calculated the photo-absorption cross-section $\sigma(E)$ of neutral and singlyionised PAHs using the real-time real-space TD-DFT implementation of the OCTOPUS computer code (Marques et al. 2003). We performed these calculations using the widely used localdensity approximation (LDA), specifically with the exchangecorrelation energy density of the homogeneous electron gas (Ceperley \& Alder 1980) parametrised by Perdew \& Zunger (1981). The comparison with the experimental data available for a few neutral PAHs (Joblin 1992; Joblin et al. 1992) shows that our results reproduce the overall far-UV behaviour up to about $30 \mathrm{eV}$. This includes the broad absorption peak dominated by $\sigma^{*} \leftarrow \sigma$ transitions, which matches well both in position and width. Concerning the low-lying excited states of $\pi^{*} \leftarrow \pi$ character occurring in the near-IR, visible, and near-UV spectral ranges, the computed vertical excitation energies are precise to within a few tenths of $\mathrm{eV}$ (in the range $0.1-0.4 \mathrm{eV}$ ), which are indeed the typical accuracies achievable by TD-DFT using hybrid or gradient-corrected exchange-correlation functionals (Hirata et al. 1999, 2003). We proved these data to be reliable enough for detailed modelling of PAHs in different charge states when laboratory data are missing (Mulas et al. 2006a,b,c). Starting from the ground-state geometries obtained as described in the previous section, we extended similar calculations to $\mathrm{PAHs}^{++}$.

In the scheme we used the wave-functions are represented by their discretised values on a uniform spatial grid. The molecule is perturbed by an impulsive electromagnetic field, and the timedependent Kohn-Sham equations are solved in real time. From the knowledge of the time-dependent induced dipole moment, $\sigma(E)$ directly follows by Fourier transform ${ }^{1}$. The calculations

1 For further details the reader is referred to the OCTOPUS web site http: //www . tddft . org/programs/octopus. 
Table 2. Complete set of different PAHs considered in this work.

\begin{tabular}{|c|c|}
\hline Name (formula) & Symmetry group \\
\hline Azulene $\left(\mathrm{C}_{10} \mathrm{H}_{8}\right)$ & $\mathrm{D}_{2 \mathrm{~h}}$ \\
\hline Naphthalene $\left(\mathrm{C}_{10} \mathrm{H}_{8}\right)$ & $\mathrm{D}_{2 \mathrm{~h}}$ \\
\hline Acenaphthylene $\left(\mathrm{C}_{12} \mathrm{H}_{8}\right)$ & $\mathrm{C}_{2 \mathrm{v}}$ \\
\hline Biphenylene $\left(\mathrm{C}_{12} \mathrm{H}_{8}\right)$ & $\mathrm{D}_{2 \mathrm{~h}}$ \\
\hline Acenaphthene $\left(\mathrm{C}_{12} \mathrm{H}_{10}\right)$ & $\mathrm{C}_{2 \mathrm{v}}$ \\
\hline Fluorene $\left(\mathrm{C}_{13} \mathrm{H}_{10}\right)$ & $\mathrm{C}_{2 \mathrm{v}}$ \\
\hline Anthracene $\left(\mathrm{C}_{14} \mathrm{H}_{10}\right)$ & $\mathrm{D}_{2 \mathrm{~h}}$ \\
\hline Phenanthrene $\left(\mathrm{C}_{14} \mathrm{H}_{10}\right)$ & $\mathrm{C}_{2 \mathrm{v}}$ \\
\hline Pyrene $\left(\mathrm{C}_{16} \mathrm{H}_{10}\right)$ & $\mathrm{D}_{2 \mathrm{~h}}$ \\
\hline Tetracene $\left(\mathrm{C}_{18} \mathrm{H}_{12}\right)$ & $\mathrm{D}_{2 \mathrm{~h}}$ \\
\hline Chrysene $\left(\mathrm{C}_{18} \mathrm{H}_{12}\right)$ & $\mathrm{C}_{2 \mathrm{~h}}$ \\
\hline Triphenylene $\left(\mathrm{C}_{18} \mathrm{H}_{12}\right)$ & $\mathrm{D}_{3 \mathrm{~h}}$ \\
\hline Benzo[a]anthracene $\left(\mathrm{C}_{18} \mathrm{H}_{12}\right)$ & $\mathrm{C}_{\mathrm{s}}$ \\
\hline Corannulene $\left(\mathrm{C}_{20} \mathrm{H}_{10}\right)$ & $\mathrm{C}_{5 \mathrm{v}}$ \\
\hline Benzo[a]pyrene $\left(\mathrm{C}_{20} \mathrm{H}_{12}\right)$ & $\mathrm{C}_{\mathrm{s}}$ \\
\hline Benzo[e]pyrene $\left(\mathrm{C}_{20} \mathrm{H}_{12}\right)$ & $\mathrm{C}_{2 \mathrm{v}}$ \\
\hline Perylene $\left(\mathrm{C}_{20} \mathrm{H}_{12}\right)$ & $\mathrm{D}_{2 \mathrm{~h}}$ \\
\hline Anthanthrene $\left(\mathrm{C}_{22} \mathrm{H}_{12}\right)$ & $\mathrm{C}_{2 \mathrm{~h}}$ \\
\hline Benzo[g,h,i]perylene $\left(\mathrm{C}_{22} \mathrm{H}_{12}\right)$ & $\mathrm{D}_{2 \mathrm{~h}}$ \\
\hline Pentacene $\left(\mathrm{C}_{22} \mathrm{H}_{14}\right)$ & $\mathrm{D}_{2 \mathrm{~h}}$ \\
\hline Coronene $\left(\mathrm{C}_{24} \mathrm{H}_{12}\right)$ & $\mathrm{D}_{6 \mathrm{~h}}$ \\
\hline Dibenzo[b,def]chrysene $\left(\mathrm{C}_{24} \mathrm{H}_{14}\right)$ & $\mathrm{C}_{2 \mathrm{~h}}$ \\
\hline Dibenzo[cd,lm]perylene $\left(\mathrm{C}_{26} \mathrm{H}_{14}\right)$ & $\mathrm{D}_{2 \mathrm{~h}}$ \\
\hline Hexacene $\left(\mathrm{C}_{26} \mathrm{H}_{16}\right)$ & $\mathrm{D}_{2 \mathrm{~h}}$ \\
\hline Bisanthene $\left(\mathrm{C}_{28} \mathrm{H}_{14}\right)$ & $\mathrm{D}_{2 \mathrm{~h}}$ \\
\hline Benzo[a]coronene $\left(\mathrm{C}_{28} \mathrm{H}_{14}\right)$ & $\mathrm{D}_{2 \mathrm{~h}}$ \\
\hline Dibenzo[bc,kl]coronene $\left(\mathrm{C}_{30} \mathrm{H}_{14}\right)$ & $\mathrm{D}_{2 \mathrm{~h}}$ \\
\hline Dibenzo[bc,ef]coronene $\left(\mathrm{C}_{30} \mathrm{H}_{14}\right)$ & $\mathrm{C}_{2 \mathrm{v}}$ \\
\hline Terrylene $\left(\mathrm{C}_{30} \mathrm{H}_{16}\right)$ & $\mathrm{D}_{2 \mathrm{~h}}$ \\
\hline Ovalene $\left(\mathrm{C}_{32} \mathrm{H}_{14}\right)$ & $\mathrm{D}_{2 \mathrm{~h}}$ \\
\hline Tetrabezo[bc,ef,kl,no]coronene $\left(\mathrm{C}_{36} \mathrm{H}_{16}\right)$ & $\mathrm{D}_{2 \mathrm{~h}}$ \\
\hline Circumbiphenyl $\left(\mathrm{C}_{38} \mathrm{H}_{16}\right)$ & $\mathrm{D}_{2 \mathrm{~h}}$ \\
\hline Circumanthracene $\left(\mathrm{C}_{40} \mathrm{H}_{16}\right)$ & $\mathrm{D}_{2 \mathrm{~h}}$ \\
\hline Quaterrylene $\left(\mathrm{C}_{40} \mathrm{H}_{20}\right)$ & $\mathrm{D}_{2 \mathrm{~h}}$ \\
\hline Circumpyrene $\left(\mathrm{C}_{42} \mathrm{H}_{16}\right)$ & $\mathrm{D}_{2 \mathrm{~h}}$ \\
\hline Hexabenzocoronene $\left(\mathrm{C}_{42} \mathrm{H}_{18}\right)$ & $\mathrm{D}_{6 \mathrm{~h}}$ \\
\hline Dicoronylene $\left(\mathrm{C}_{48} \mathrm{H}_{20}\right)$ & $\mathrm{D}_{2 \mathrm{~h}}$ \\
\hline Pentarylene $\left(\mathrm{C}_{50} \mathrm{H}_{8}\right)$ & $\mathrm{D}_{2 \mathrm{~h}}$ \\
\hline Circumcoronene $\left(\mathrm{C}_{54} \mathrm{H}_{18}\right)$ & $\mathrm{C}_{6 \mathrm{~h}}$ \\
\hline Circumovalene $\left(\mathrm{C}_{66} \mathrm{H}_{20}\right)$ & $\mathrm{D}_{2 \mathrm{~h}}$ \\
\hline
\end{tabular}

for $\mathrm{PAHs}^{++}$are almost the same as in Malloci et al. (2004), where a thorough description can be found. As already done for anions (Malloci et al. 2005), we added an absorbing boundary, which quenches spurious resonances due to standing waves in the finite simulation box (Yabana \& Bertsch 1999; Marques et al. 2003).

The photo-absorption spectra of a few $\mathrm{PAHs}^{++}$reported by Witt et al. (2006) were obtained with a different implementation of TD-DFT, which is based on the identification of the poles of the linear response function (Casida 1995). In this scheme, computational costs scale steeply with the number of required transitions, and the excitation spectra are limited to the low-energy part of the spectrum (e.g., Hirata et al. 1999, 2003). The advantages of the real-time propagation method used here are discussed by Lopez et al. (2005). From the astrophysical point of view, the main step forward we achieved by using this approach lies in the spectral range covered, which extends up to the excitable energies in a typical interstellar source. At the same time, the main drawback is that we do not obtain independent information for each excited electronic state, such as its symmetry and its description in terms of the promotion of electrons in a one-electron picture.

\section{Results}

All neutral and singly-ionised species were computed as singlet and doublet, respectively, while for dications we computed both their singlet and triplet ground states. This enabled us to predict the relative energies of electronic states having different multiplicities. For almost all of the molecules under study (34 out of a total of 40), our calculations predict the dication overall ground-state to be the singlet. In the other cases - the dications of acenaphtylene, triphenylene, corannulene, coronene, hexabenzocoronene, and circumcoronene - the predicted energy difference between the singlet and triplet states is in the range $0.03-0.36 \mathrm{eV}$, which cannot unambiguously identify the ground state, given the accuracy of the method we used. In this respect DFT-based methods are known to be limited in the evaluation of accurate energetic ordering of very close electronic states having different multiplicities (Schröder et al. 2001). In addition, the B3LYP functional is thought to be biased towards higher spin states (Bauschlicher \& Bakes 2000), and better levels of wave function favour the singlet state over the triplet (Rosi et al. 2004).

\subsection{Single and double ionisation energies}

For each species we derived single and double AIEs, respectively, as total energy differences between the geometryoptimised cations and dications and the total energy of the geometry optimised neutral molecules. The corresponding VIEs were evaluated as the differences between the single-point energy of the cation and dication at the optimised neutral geometry and the total energy of the optimised neutral species. The adiabatic second ionisation energy $\Delta I$ is simply given by $I_{\text {ad }}^{++}-I_{\text {ad }}^{+}$, while its vertical value is obtained through the difference between the single-point energy of the dication at the optimised cation geometry and the total energy of the optimised cation. These results are listed in Table A.1 of the Appendix and sketched in Fig. 1 as a function of the number of carbon atoms in the molecule. The differences between vertical and adiabatic ionisation energies are found to decrease as the size of the molecule increases. In all cases, however, and as already found by Schröder et al. (2001), these values are relatively low, being of the order of $0.1 \mathrm{eV}$ for first and second IEs and falling in the range $0.1-0.5 \mathrm{eV}$ for double IEs.

\subsection{IR spectral properties}

All the computed harmonic vibrational frequencies of the $\mathrm{PAHs}^{++}$considered, also for their corresponding anions, neutrals, and cations, can be found in our online database of the computed spectral properties of PAHs, which is presently under construction (Malloci et al. 2006). We report here only comparative plots for the IR properties of the PAHs under study in their $0,+1$, and +2 charge states. In agreement with previous works (Ellinger et al. 1999; Bauschlicher \& Bakes 2000; Pauzat \& Ellinger 2002), we found that, while the harmonic vibrational frequencies are only slightly affected by single and double ionisation, absolute and relative IR absorption crosssections undergo significant variations with charge. Figure 2 displays the fractions of the total integrated IR absorption crosssection in the four spectral ranges $2.5-3.5,5-10,10-15 \mu \mathrm{m}$, and $>15 \mu \mathrm{m}$ as a function of the total carbon atoms in the molecule. These wavelength intervals are somewhat arbitrary but roughly contain the spectral signatures of, respectively: $\mathrm{C}-\mathrm{H}$ stretchings $(2.5-3.5 \mu \mathrm{m}), \mathrm{C}-\mathrm{C}$ in-plane stretchings and $\mathrm{C}-\mathrm{H}$ in-plane 


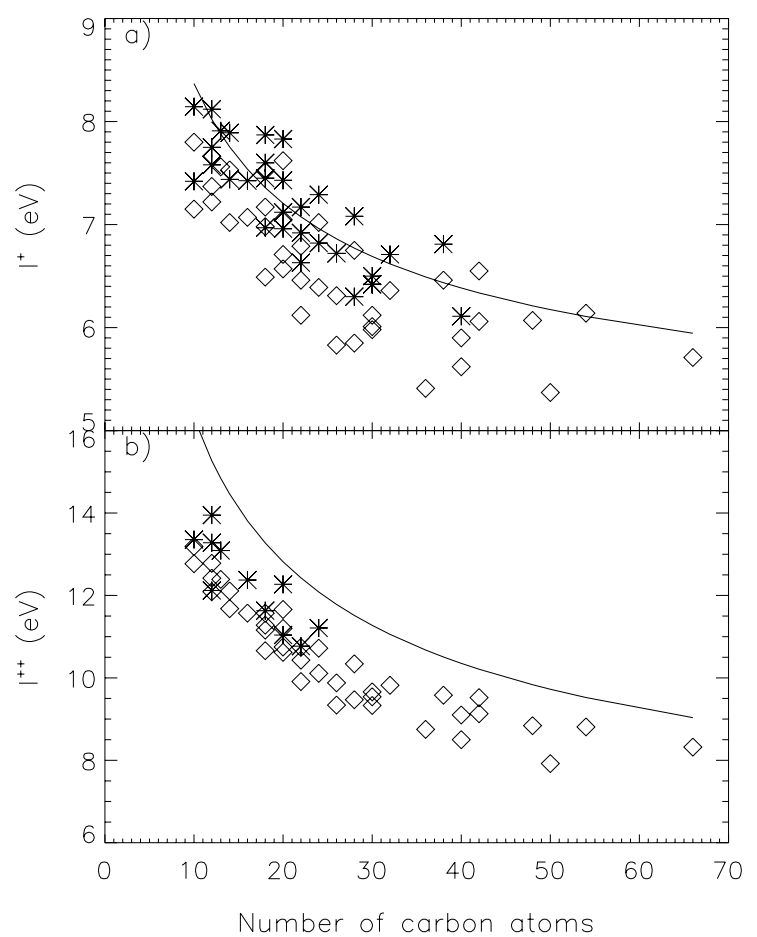

Fig. 1. Comparison between experimental (asterisks) and computed (diamonds) first a) and second b) AIEs for the 40 PAHs considered in this work as a function of the number of carbon atoms in the molecule. The continuous line is an empirical estimate (Tielens 2005, p. 191).

bendings $(5-10 \mu \mathrm{m}), \mathrm{C}-\mathrm{H}$ out of plane bendings $(10-15 \mu \mathrm{m})$, and in-plane and out-of-plane cycle deformations of the whole carbon skeleton $(>15 \mu \mathrm{m})$. The lowest panel of Fig. 2 shows the absolute value of the total integrated IR absorption crosssection divided by the number of carbon atoms $N_{C}$. In Fig. 2 we omitted the vibrational data we obtained for the more symmetric molecules, for which Jahn-Teller distortion is observed upon ionisation. For example, in the specific cases of the cations of triphenylene and coronene, two different Jahn-Teller distorted structures are known to exist (Torii 1999; Kato et al. 1999). These two configurations are very close in energy, and the determination of the most stable structure is a delicate problem that may complicate DFT-based calculations and severely affect the resulting IR spectra (Oomens et al. 2001). We report in Fig. 3 the corresponding data of Fig. 2 given only for a specific series of PAHs, namely the oligorylenes perylene, terrylene, quaterrylene and pentarylene $\left(\mathrm{C}_{10 n} \mathrm{H}_{4 n+4}\right.$, with $\left.n=2,3,4,5\right)$.

As to the accuracy of our B $3 \mathrm{LYP} / 4-31 \mathrm{G}$ data, this method seems to overestimate the intensities of $\mathrm{C}-\mathrm{H}$ stretching modes (Langhoff 1996; Bauschlicher \& Langhoff 1997). The evaluation of absolute IR absorption cross-sections is a difficult task since they are known to be strongly affected by the specific choice of the basis set employed (Langhoff 1996; Bauschlicher \& Langhoff 1997). This holds true, in particular, for openshell species that may present problems of spin contamination or charge localisation artifacts. As an example, the total integrated IR absorption cross-sections we obtain for pyrene neutral, cation, and dication are $464.4,784.6$, and $1758.3 \mathrm{~km} / \mathrm{mol}$, while the calculations of Ellinger et al. (1999) performed at the higher B3LYP/6-31G ${ }^{\star}$ level, give $399.3,720.9$, and $1613.5 \mathrm{~km} / \mathrm{mol}$, respectively. The intensity ratios in the same wavelength intervals introduced above are almost coincident among the two sets of results for $\mathrm{C}_{16} \mathrm{H}_{10}$ and $\mathrm{C}_{16} \mathrm{H}_{10}{ }^{++}$. In the case of the cation $\mathrm{C}_{16} \mathrm{H}_{10}{ }^{+}$, instead, these values amount to $2,68,27$, and $3 \%$, to

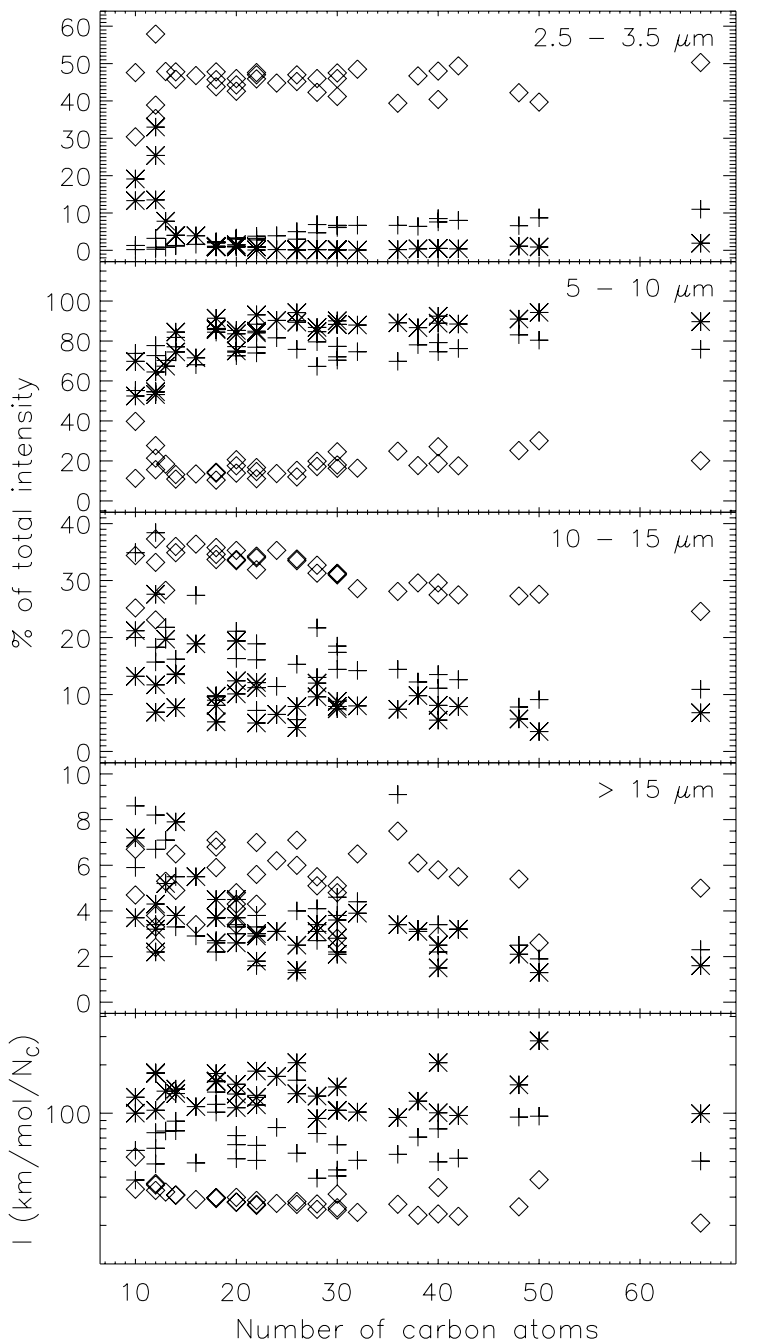

Fig. 2. Comparison between the fraction of the total integrated IR absorption cross-section in the spectral ranges $2.5-3.5,5-10,10-15 \mu \mathrm{m}$, and $>15 \mu \mathrm{m}$ for the neutrals (diamonds), cations (crosses), and dications (asterisks) of the PAHs considered as a function of the number of carbon atoms $N_{\mathrm{C}}$. The lowest panel shows the absolute total integrated IR absorption cross-sections $I$ (in $\mathrm{km} / \mathrm{mol}$ ), divided by $N_{\mathrm{C}}$.

be compared with 1, 71, 19 and 9\%, as obtained by Ellinger et al. (1999).

\subsection{Photo-absorption spectra}

As for the computed vibrational properties, all the theoretical photo-absorption spectra of the $\mathrm{PAHs}^{++}$considered and their neutral and singly-ionised counterparts can be found in our online database. For the low-lying $\pi^{\star} \leftarrow \pi$ transitions occurring in the near-IR, visible, and near-UV spectral ranges, the application of this approach to PAHs and $\mathrm{PAHs}^{ \pm}$was shown to be as accurate as previously published theoretical results, compared to the available experimental data (Malloci et al. 2004, 2005). However, while we established the use of the OcTOPUs code to calculate reasonably accurate photo-absorption spectra of neutral PAHs up to the vacuum-UV spectral range, experimental spectra in the far-UV are needed for a similar direct validation for PAH ions. The computed vertical excitation energies are expected to be precise to within a few tenths of an $\mathrm{eV}$, which are the typical accuracies of TD-DFT calculations employing the currently available exchange-correlation functionals 


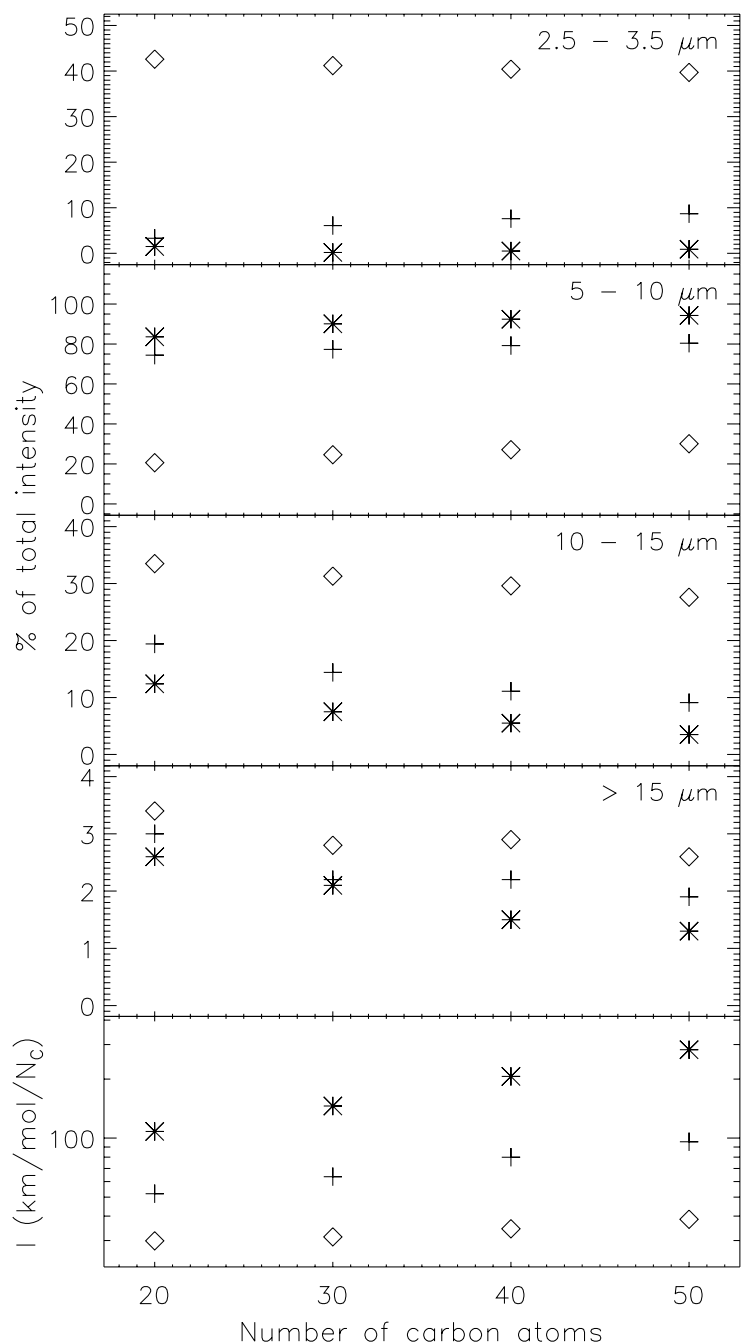

Fig. 3. Same as Fig. 2, restricted to the PAHs of the oligoarylenes series, i.e., perylene, terrylene, quaterrylene, and pentarylene $\left(\mathrm{C}_{10 n} \mathrm{H}_{4 n+4}\right.$, with $n=2,3,4,5$ ).

(Hirata et al. 1999, 2003; Weisman et al. 2001, 2003, 2005). More specifically, depending on the character of the specific transition, TD-DFT can reach the same accuracy as more sophisticated and expensive wave-function based methods or show substantial errors, as in the case of the lowest short-axis polarised states in the oligoacenes (Grimme \& Parac 2003).

The spectra obtained for $\mathrm{PAHs}^{++}$can be compared with the corresponding ones of PAHs and $\mathrm{PAHs}^{+}$. Figure 4 shows weighted averages of the electronic photo-absorption spectra of the same sample of PAHs, respectively, in the neutral, cationic, and dicationic state. To make the changes occurring for specific molecules apparent, Figs. 5 and 6 compare the photo-absorption cross-sections of benzo[a]anthracene $\left(\mathrm{C}_{18} \mathrm{H}_{12}\right)$ and circumanthracene $\left(\mathrm{C}_{40} \mathrm{H}_{16}\right)$ as a function of an increasing positive-charge state.

\section{Discussion}

The values we found for the second AIEs confirm that PAHs ${ }^{++}$ can be expected to be produced by two-step ionisation in the ISM.

The computed positions of the IR bands are relatively similar for the same PAH in different charge states, as already noted in previous studies of a few $\mathrm{PAH}$ dications

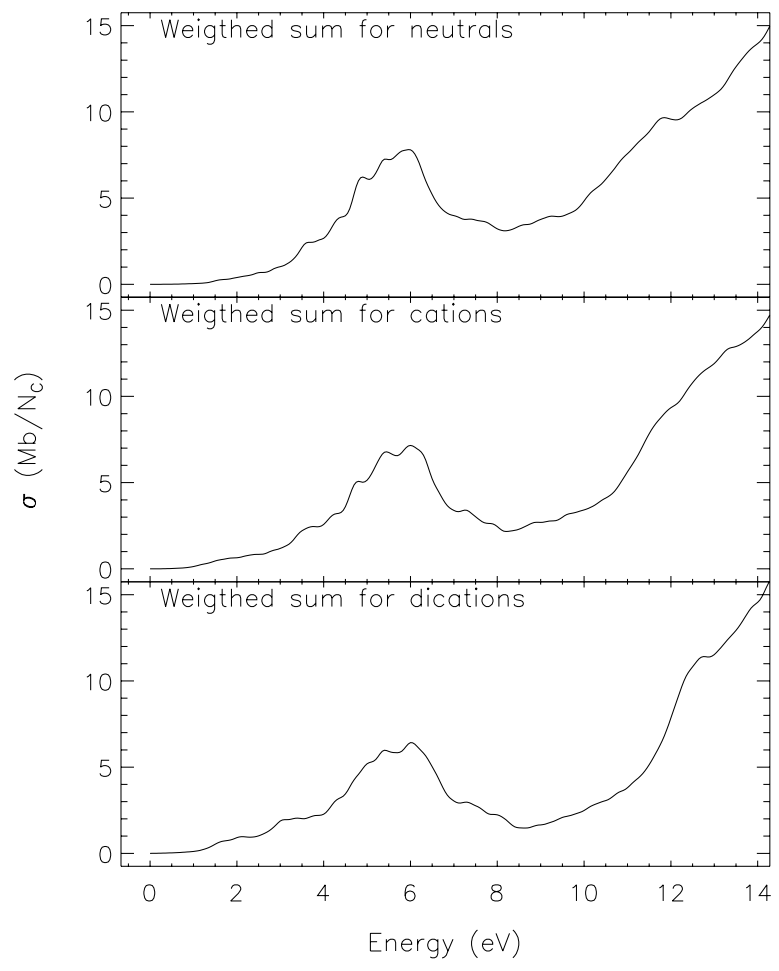

Fig. 4. Comparison between the weighted sum of the computed photoabsorption cross-sections $\sigma(E)$ (expressed in Megabarns $/ N_{\mathrm{C}}, 1 \mathrm{Mb}=$ $10^{-18} \mathrm{~cm}^{2}$ ) for PAH neutrals, the corresponding cations, and dications. We used the inverse of the total number of carbon atoms $N_{\mathrm{C}}$ of each molecule as weight.

(Ellinger et al. 1999; Bauschlicher \& Bakes 2000; Pauzat \& Ellinger 2002). We confirm that there are systematic shifts in some band positions as a function of the ionisation state, which only slightly change the general pattern. We concentrate on the much larger variations in the integrated absorption crosssections. The latter change by one order of magnitude, for some bands, due to drastic changes in charge distribution following ionisation. Our sample of molecules is quite heterogeneous, so Fig. 2 may be somewhat confusing due to crowding. However, general trends versus molecular size and versus charge can still be observed, and are more evident upon examinating sequences of molecules of the same class, as Fig. 3 clearly shows for the oligorylenes series. From the top panels of Figs. 2 and 3, we see the well-known collapse of the intensities of $\mathrm{C}-\mathrm{H}$ stretching modes for singly-ionised species (De Frees et al. 1993; Langhoff 1996). The same is observed for doublyionised species (Bauschlicher \& Bakes 2000) with the exception of small PAHs up to $\sim 16$ carbon atoms, in which the intensity of these modes is partly restored by double ionisation (Ellinger et al. 1999; Pauzat \& Ellinger 2002). A net increase in the intensity of the in-plane $\mathrm{C}-\mathrm{H}$ band and $\mathrm{C}-\mathrm{C}$ stretching vibrations is observed for $\mathrm{PAHs}^{+}$with respect to neutral species in the $5-10 \mu \mathrm{m}$ window. This occurs even to a larger extent for $\mathrm{PAHs}^{++}$, whose absorption spectra tend to be dominated only by the features in this region. The opposite is observed in the $10-15 \mu \mathrm{m}$ interval, where the out-of-plane $\mathrm{C}-\mathrm{H}$ vibrations are the second major component for neutral species but tend to be less important for $\mathrm{PAHs}^{+}$and $\mathrm{PAHs}^{++}$. Bands at wavelengths larger than $15 \mu \mathrm{m}$ contribute for less than $10 \%$ of the total integrated IR absorption cross-section $I$. The absolute value of the latter quantity, for all of the molecules considered, shows a marked increase upon ionisation, as clearly demonstrated by 


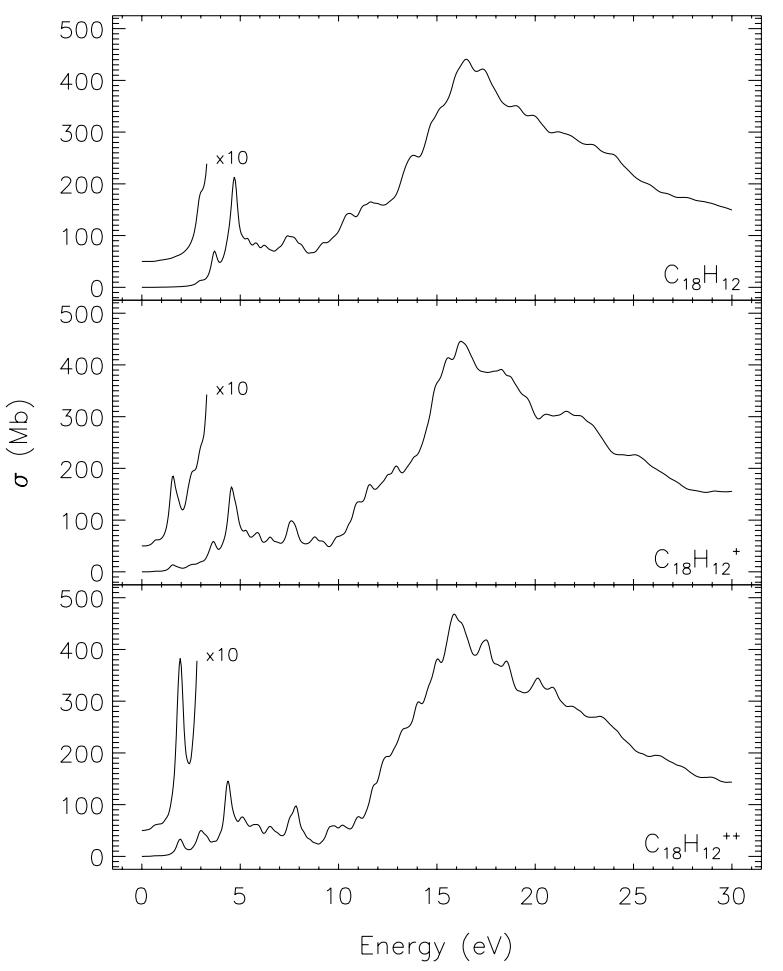

Fig. 5. Photo-absorption cross-section $\sigma(E)$ of benzo[a]anthracene $\left(\mathrm{C}_{18} \mathrm{H}_{12}\right)$ in the three charge states $0,+1$ and +2 . Units for $\sigma(E)$ are Megabarns $\left(1 \mathrm{Mb}=10^{-18} \mathrm{~cm}^{2}\right)$.

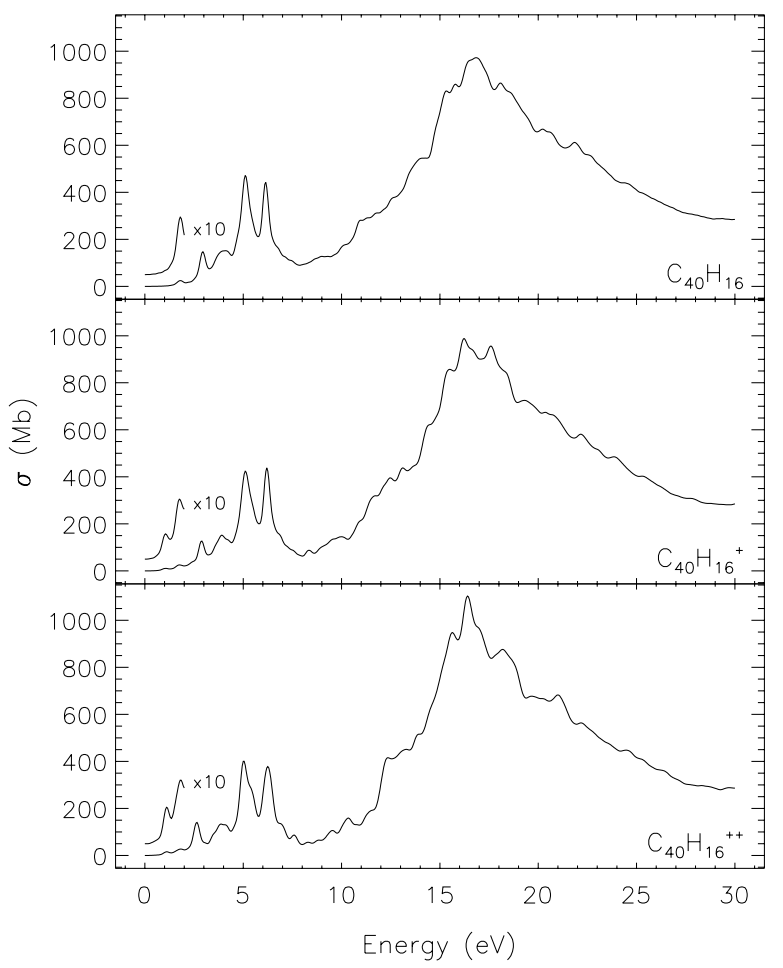

Fig. 6. Same as Fig. 5 for circumanthracene $\left(\mathrm{C}_{40} \mathrm{H}_{16}\right)$.

the lowest panel of Figs. 2 and 3. On average we found that $\mathrm{PAHs}^{++}$absorb about $2.5 \pm 1.0$ times more than their parent singly-ionised molecules and about $4.7 \pm 1.1$ times more than their parent neutrals.

With respect to the electronic absorption properties, inspection of Figs. 5 and 6 shows that all the spectra for specific

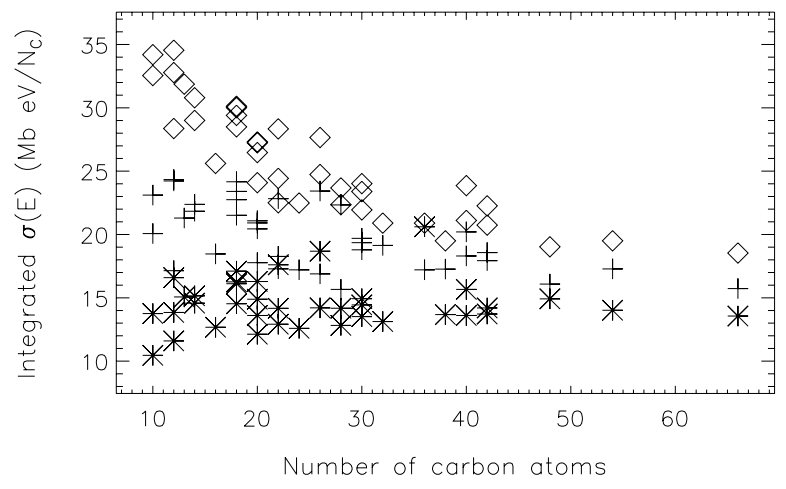

Fig. 7. Comparison between the integrated values between $\sim 7$ and $\sim 12 \mathrm{eV}$ of the photo-absorption cross-sections $\sigma(E)$ divided by the number of carbon atoms $N_{\mathrm{C}}$, for the neutrals (diamonds), cations (crosses), and dications (asterisks) of the PAHs considered, as a function of $N_{\mathrm{C}}$.

molecules show comparable features in the UV range, displaying the same behaviour already known for neutral species (Joblin 1992; Joblin et al. 1992; Leach 1995), i.e., increasing smoothly at energies above $\sim 7.4 \mathrm{eV}$ to a maximum at $\sim 17.4 \mathrm{eV}$ in a single broad absorption peak composed of $\sigma^{*} \leftarrow \sigma, \sigma^{*} \leftarrow \pi, \pi^{*} \leftarrow \sigma$ and Rydberg spectral transitions. The onset of this broad absorption moves blueward and becomes steeper with increasing positive charge, following the increase in subsequent ionisation potentials. This translates into a systematic decrease in the crosssection between $\sim 7$ and $\sim 12 \mathrm{eV}$ with increasing positive charge, as shown in Fig. 7. In the near-IR, visible, and near-UV spectral ranges, the dication has strong absorption features of a $\pi^{\star} \leftarrow \pi$ character, like the singly-ionised species. Such behaviour is an expected consequence of the different one-electron energy levels and of the resulting first few electric dipole-permitted transitions.

More generally, Fig. 4 shows that the three averaged spectra present very similar features. The main difference is the progressive decrease, with increasing positive charge, in the crosssection between $\sim 7$ and $\sim 12 \mathrm{eV}$, as expected from the behaviour of the individual spectra in this same energy interval (cf. Fig. 7). Both the former similarity and the latter difference have interesting astrophysical implications for the UV range of the spectrum: apart from small details (i.e., the precise position of single, specific transitions of a single, specific molecule), the contribution of any given PAH will depend only slightly on its ionisation state. The average over a sample of molecules has the main effect of smoothing out the detailed structure resulting from the contribution of each single species. This confirms our previous findings (Joblin 1992; Joblin et al. 1992; Malloci et al. 2004, 2005), extending them to $\mathrm{PAHs}^{++}$: if any PAHs of small-to-medium size, be they neutral, cationic, or dicationic, are to account for the far-UV rise of the interstellar extinction curve they must also contribute to the short-wavelength side of the interstellar extinction bump at $\sim 2175 \AA(\sim 5.7 \mathrm{eV})$. On the other hand, the onset of the far-UV rise produced by PAHs ought to depend on their charge state, therefore comparison with observed extinction curves could provide an observational handle for estimating the average charge state of interstellar PAHs.

The photo-stability of $\mathrm{PAHs}^{++}$deserves further investigation: given the photo-absorption spectra we have obtained, $\mathrm{PAHs}^{++}$will efficiently absorb UV photons, if available, and can be expected to convert at least a fraction of the resulting energy to internal excitation, possibly reaching their dissociation threshold. Should this be the case, this might turn out to 
be a major destruction channel for PAHs. However, $\mathrm{PAHs}^{++}$ absorb slightly less than their parent neutral molecules and singly ionised species between $\sim 7$ and $\sim 12 \mathrm{eV}$, and cool faster by IR fluorescence since, as we saw before, their vibrational transitions are usually from two to five times more intense. Since in these molecules unimolecular dissociation is expected to occur in competition with vibrational cooling, $\mathrm{PAHs}^{++}$should actually be much more stable against photodissociation than PAHs and $\mathrm{PAHs}^{+}$if the dissociation thresholds are nearly unchanged by ionisation. More laboratory studies of the relaxation paths of $\mathrm{PAHs}^{++}$following photon absorption are needed.

\section{Conclusions and future work}

We performed a systematic theoretical study of the ionisation energies of PAHs and the IR and visible-UV absorption properties of their dications. The values we found for the second IEs confirm that PAHs could reach the doubly-ionised state in $\mathrm{HI}$ regions. Combining the IR and visible-UV absorption properties of $\mathrm{PAHs}^{++}$, we predict an increased photostability for these species with respect to their neutral and singly-ionised parent molecules, unless they have lower dissociation channels.

The recent paper by Witt et al. (2006) has recently renewed interest in the dications of PAHs, proposing them as plausible candidates of the extended red emission. The fundamental data we present here for a large sample of different PAHs will be useful for modelling the photophysics of these molecules in detail in interstellar conditions. For instance, we can quantitatively estimate the complete IR emission spectrum of each molecule in the sample as a function of its charge state, for direct comparison with data from the Infrared Space Observatory and Spitzer Space Telescope missions and, in the near future, from the Herschel Space Observatory mission (Mulas et al. 2006a,b,c). In addition, combined with measurements of the electron recombination rates of singly-ionised PAHs (Novotný et al. 2005) and their extension to doubly-ionised species, which still have to be studied, the present work opens the way to a detailed modelling of the chemistry and photophysics of PAHs in interstellar environments (Bakes \& Tielens 1998; Le Page et al. 2001) where they may play a prominent role.

Acknowledgements. G. Malloci acknowledges financial support by the "Ministère de la Recherche". We warmly thank the authors of OCTOPUS for making their code available under a free license. We acknowledge the High Performance Computational Chemistry Group for the use of NWChem, A Computational Chemistry Package for Parallel Computers, Version 4.7 (2005), PNNL, Richland, Washington, USA. Part of the calculations were performed using the CINECA and CALMIP supercomputing facilities.

\section{References}

Allamandola, L. J., Tielens, A. G. G. M., \& Barker, J. R. 1985, ApJ, 290, L25 Allamandola, L. J., Tielens, G. G. M., \& Barker, J. R. 1989, ApJS, 71, 733 Apra, E., Windus, T. L., Straatsma, T. P., et al. 2005, NWChem, A Computational Chemistry Package for Parallel Computers, Version 4.7

Bakes, E. L. O., \& Tielens, A. G. G. M. 1998, ApJ, 499, 258

Bakes, E. L. O., Tielens, A. G. G. M., \& Bauschlicher, C. W. 2001a, ApJ, 556, 501

Bakes, E. L. O., Tielens, A. G. G. M., Bauschlicher, C. W., Hudgins, D. M., \& Allamandola, L. J. 2001b, ApJ, 560, 261

Barker, J. R. 1983, Chem. Phys., 77, 301

Bauschlicher, C. W. 2002, ApJ, 564, 782

Bauschlicher, C. W., \& Bakes, E. L. O. 2000, Chem. Phys., 262, 285

Bauschlicher, C. W., \& Bakes, E. L. O. 2001, Chem. Phys., 274, 11

Bauschlicher, C. W., \& Langhoff, S. R. 1997, Spectrochimica Acta Part A, 53, 1225

Becke, A. D. 1993, J. Chem. Phys., 98, 5648

Becke, A. D. 1997, J. Chem. Phys., 107, 8554
Boulanger, F. 1999, in Solid Interstellar Matter: The ISO Revolution, ed. L. d'Hendecourt, C. Joblin, \& A. Jones (Les Ulis: EDP Sciences), 20

Casida, M. E. 1995, in Recent Advances in Density Functional Theory. Vol. I, ed. D. P. Chong (Singapore: World Scientific)

Ceperley, D. M., \& Alder, B. J. 1980, Phys. Rev. Lett., 45, 566

Crawford, M. K., Tielens, A. G. G. M., \& Allamandola, L. J. 1985, ApJ, 293, L45

De Frees, D. J., Miller, M. D., Talbi, D., Pauzat, F., \& Ellinger, Y. 1993, ApJ, 408, 530

Deleuze, M. S., Claes, L., Kryachko, E. S., \& François, J.-P. 2003, J. Chem. Phys., 119, 3106

Dessent, C. E. H. 2000, Chem. Phys. Lett., 330, 180

Draine, B. T. 2003, ARA\&A, 41, 241

Dunning, T. H. 1989, J. Chem. Phys., 90, 1007

Ehrenfreund, P., \& Charnley, S. B. 2000, ARA\&A, 38, 427

Eilfeld, P., \& Schmidt, W. 1981, J. El. Spctr. Rel. Phen., 24, 101

Ellinger, Y., Pauzat, F., \& Lengsfield, B. H. 1999, Journal of Molecular Structure (Theochem), 458, 203

Fitzpatrick, E. L. 2004, in Astrophysics of Dust, ASP Conf. Ser., 309, 33

Frisch, M. J., Trucks, G. W., Schlegel, H. B., et al. 2003, Gaussian 03, Revision B.05, Gaussian Inc., Pittsburgh PA

Frish, M. J., Pople, J. A., \& Binkley, J. S. 1984, J. Chem. Phys., 80, 3265

Fulara, J., \& Krelowski, J. 2000, New Astron. Rev., 44, 581

Grimme, S., \& Parac, M. 2003, Chem. Phys. Chem., 3, 292

Halasinski, T. M., Hudgins, D. M., Salama, F., Allamandola, L. J., \& Bally, T. 2000, J. Phys. Chem. A, 104, 7484

Halasinski, T. M., Weisman, J., Ruiterkamp, R., et al. 2003, J. Phys. Chem. A, 107,3660

Hamprecht, F. A., Cohen, A. J., Tozer, D. J., \& Handy, N. C. 1998, J. Chem. Phys., 109, 6264

Heinze, H. H., Görling, A., \& Rösch, N. 2000, J. Chem. Phys., 113, 2088

Herbig, G. H. 1995, ARA\&A, 33, 19

Hirata, S., Head-Gordon, M., Szczepanski, J., \& Vala, M. 2003, J. Phys. Chem. A, 107, 4940

Hirata, S., Lee, T., \& Head-Gordon, M. 1999, J. Chem. Phys., 111, 8904

Joblin, C. 1992, Ph.D. Thesis, Université Paris 7

Joblin, C., Léger, A., \& Martin, P. 1992, ApJ, 393, L79

Joblin, C., Toublanc, D., Boissel, P., \& Tielens, A. G. G. M. 2002, Mol. Phys., 100,3595

Jolibois, F., Klotz, A., Gadéa, F. X., \& Joblin, C. 2005, A\&A, 444, 629

Jones, R. O., \& Gunnarsson, O. 1989, Rev. Mod. Phys., 61, 689

Kadantsev, E. S., Stott, M. J., \& Rubio, A. 2006, J. Chem. Phys., 124, 134901

Kato, T., \& Yamabe, T. 2002, J. Chem. Phys., 117, 2324

Kato, T., Yoshizawa, K., \& Yamabe, T. 1999, J. Chem. Phys., 110, 249

Langhoff, S. R. 1996, J. Phys. Chem., 100, 2819

Leach, S. 1986, J. El. Spctr. Rel. Phen., 41, 427

Leach, S. 1987, in Polycyclic Aromatic Hydrocarbons and Astrophysics, NATO ASIC Proc., 191, 99

Leach, S. 1989, in Interstellar Dust, IAU Symp., 135, 155

Leach, S. 1995, Planet. Space Sci., 43, 1153

Leach, S. 1996, Zeitschr. f. Physik. Chem., 195, 15

Leach, S., Eland, J. H. D., \& Price, S. D. 1989a, J. Phys. Chem., 93, 7575

Leach, S., Eland, J. H. D., \& Price, S. D. 1989b, J. Phys. Chem., 93, 7583

Ledingham, K. W. D., Smith, D. J., Singhal, R. P., et al. 1999, J. Phys. Chem. A, 103,2952

Lee, C., Yang, W., \& Parr, R. 1988, Phys. Rev. B, 37, 785

Léger, A., \& d'Hendecourt, L. 1985, A\&A, 146, 81

Léger, A., \& Puget, J. L. 1984, A\&A, 137, L5

Le Page, V., Snow, T., \& Bierbaum, V. 2001, ApJS, 132, 233

Lias, S. 2005, in NIST Chemistry WebBook, NIST Standard Reference Database Number 69, ed. P. J. Linstrom, \& W. G. Mallard (Gaithersburg MD: National Institute of Standards and Technology - http://webbook.nist.gov)

Lopez, X., Marques, M. A. L., Castro, A., \& Rubio, A. 2005, J. Am. Chem. Soc., 127,12329

Malloci, G., Joblin, C., \& Mulas, G. 2006, in preparation

Malloci, G., Mulas, G., \& Benvenuti, P. 2003, A\&A, 410, 623

Malloci, G., Mulas, G., Cappellini, G., Fiorentini, V., \& Porceddu, I. 2005, A\&A, 432, 585

Malloci, G., Mulas, G., \& Joblin, C. 2004, A\&A, 426, 105

Marques, M. A. L., Castro, A., Bertsch, G. F., \& Rubio, A. 2003, Comput. Phys. Commun., 151, 60

Marques, M. A. L., \& Gross, E. K. U. 2004, Ann. Rev. Phys. Chem., 55, 3425

Martin, J. M. L., El-Yazal, J., \& Francois, J. 1996, J. Phys. Chem., 100, 15358

Millar, T. J. 1992, MNRAS, 259, 35P

Mulas, G. 1998, A\&A, 338, 243

Mulas, G., Malloci, G., \& Benvenuti, P. 2003, A\&A, 410, 639

Mulas, G., Malloci, G., Joblin, C., \& Toublanc, D. 2006a, A\&A, 456, 161

Mulas, G., Malloci, G., Joblin, C., \& Toublanc, D. 2006b, A\&A, 460, 93 
Mulas, G., Malloci, G., Joblin, C., \& Toublanc, D. 2006c, A\&A, 446, 537 Novotný, O., Sivaraman, B., Rebrion-Rowe, C., et al. 2005, J. Chem. Phys., 123, 4303

Omont, A. 1986, A\&A, 164, 159

Oomens, J., Sartakov, B. G., Tielens, A. G. G. M., Meijer, G., \& von Helden, G. 2001, ApJ, 560, L99

Parac, M., \& Grimme, S. 2003, Chem. Phys., 292, 11

Pauzat, F., \& Ellinger, Y. 2002, Chem. Phys., 280, 267

Peeters, E., Allamandola, L. J., Hudgins, D. M., Hony, S., \& Tielens, A. G. G. M. 2004, in Astrophysics of Dust, ASP Conf. Ser., 309, 141

Perdew, J. P., \& Zunger, A. 1981, Phys. Rev. B, 23, 5048

Puget, J. L., \& Léger, A. 1989, ARA\&A, 27, 161

Rienstra-Kiracofe, J. C., Barden, C. J., Brown, S. T., \& Schaefer III, H. F. 2001, J. Phys. Chem. A, 105, 524

Rosi, M., Bauschlicher, C. W., \& Bakes, E. L. O. 2004, ApJ, 609, 1192

Schröder, D., Loos, J., Schwarz, H., et al. 2001, Helv. Chim. Acta, 84, 1625

Tielens, A. G. G. M. 2005, The Physics and Chemistry of the Interstellar Medium (Cambridge: Cambridge University Press)
Tobita, S., Leach, S., Jochins, H. W., et al. 1994, Canadian Journal of Physics, 72,1060

Torii, H. 1999, Chem. Phys. Lett., 306, 381

van der Zwet, G. P., \& Allamandola, L. 1985, A\&A, 146, 76

Vijh, U. P., Witt, A. N., \& Gordon, K. D. 2004, ApJ, 606, L65

Vijh, U. P., Witt, A. N., \& Gordon, K. D. 2005a, ApJ, 633, 262

Vijh, U. P., Witt, A. N., \& Gordon, K. D. 2005b, ApJ, 619, 368

Weisman, J. L., Lee, T. J., \& Head-Gordon, M. 2001, Spectrochim. Acta Part A, 57,931

Weisman, J. L., Lee, T. J., Salama, F., \& Head-Gordon, M. 2003, ApJ, 587, 256 Weisman, J. L., Mattioda, A., Lee, T. J., et al. 2005, Phys. Chem. Chem. Phys., 7, 109

Wiberg, K. B. 1997, J. Org. Chem., 62, 5720

Witt, A. N., Gordon, K. D., Vijh, U. P., et al. 2006, ApJ, 636, 303

Witt, A. N., \& Vijh, U. P. 2004, in Astrophysics of Dust, ASP Conf. Ser., 309, 115

Woon, D. E., \& Park, J.-Y. 2004, ApJ, 607, 342

Yabana, K., \& Bertsch, G. F. 1999, Int. J. Q. Chem., 75, 55 
G. Malloci et al.: Theoretical evaluation of PAH dication properties, Online Material $p 1$

\section{Online Material}




\section{Appendix A: Computed adiabatic and vertical single and double IEs}

The following Table A.1 lists the single and double adiabatic and vertical IEs for each molecule considered in this work. As explained in the body of the paper, the single and double AIEs were computed, respectively, via total energy differences between the geometry optimised cations and dications and the total energy of the geometry optimised neutral. The corresponding VIEs were evaluated as the differences between the single-point energy of the cation and dication at the optimised neutral geometry and the total energy of the optimised neutral. The adiabatic second ionisation energy $\Delta I$ is simply given by $I_{\text {ad }}^{++}-I_{\text {ad }}^{+}$, while its vertical value is obtained through the difference between the singlepoint energy of the dication at the optimised cation geometry and the total energy of the optimised cation. We also evaluated the energy difference between the direct vertical double ionisation process $\left(\mathrm{PAH} \rightarrow \mathrm{PAH}^{++}\right)$and the intermediate one in which the mono-cation is allowed to relax to its ground-state geometry before second ionisation $\left(\mathrm{PAH} \rightarrow \mathrm{PAH}^{+} \rightarrow \mathrm{PAH}^{++}\right.$). The last two columns of Table A.1 report the sum of the first and second vertical ionisation energies $I_{\mathrm{V}}^{+}+\Delta I_{\mathrm{V}}$ and the difference between the double vertical ionisation energy $I_{\mathrm{V}}^{++}$and $I_{\mathrm{V}}^{+}+\Delta I_{\mathrm{V}}$.

For all singlet dications under study, it is found that the intermediate formation of the monocation is less energy-demanding than the direct double-ionisation process (the above difference being positive); the opposite sign is instead obtained for almost all triplet dications. As pointed out by Schröder et al. (2001), this comes from the triplet dication geometries being more similar to the neutral ground-state geometries than to the ones of the monocation. 

$\pm$

乙ะ一𠃌

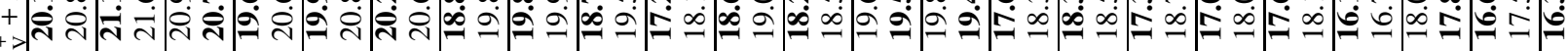
$+\geq$

离

\begin{tabular}{|c|c|c|c|c|c|c|c|}
\hline $\begin{array}{c}n \\
0 \\
+1 \\
n \\
n\end{array}$ & 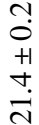 & 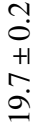 & 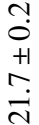 & $\begin{array}{l}\text { Na } \\
0 \\
+1 \\
0 \\
\\
\end{array}$ & 1 & 1 & $\begin{array}{l}2 \\
0 \\
+1 \\
\infty \\
0\end{array}$ \\
\hline
\end{tabular}

我 $\Rightarrow$ ते ๑

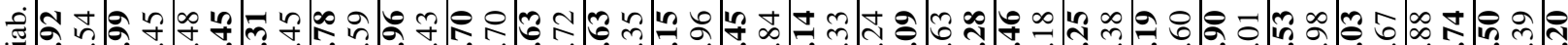

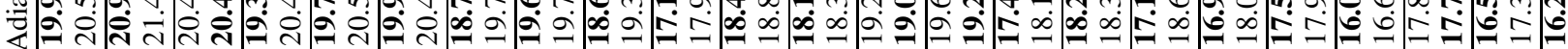
1
বl
1

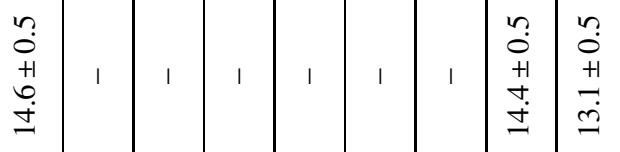

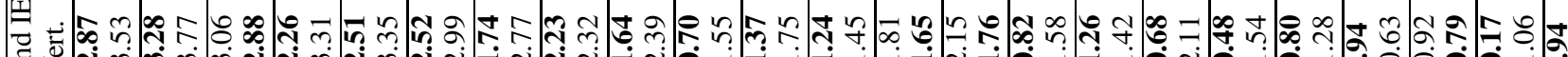

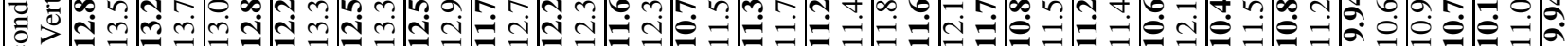

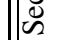

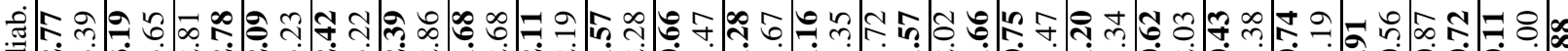

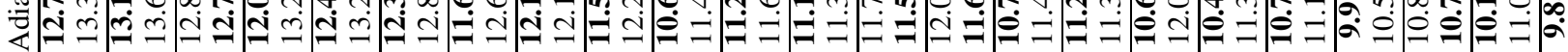

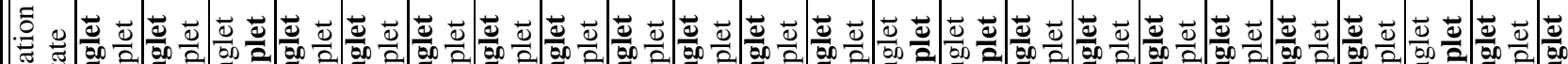

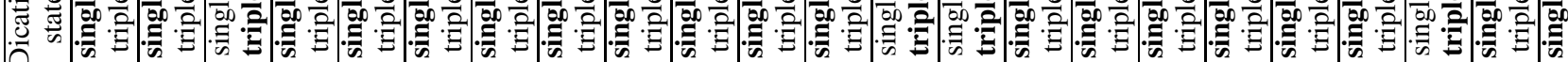

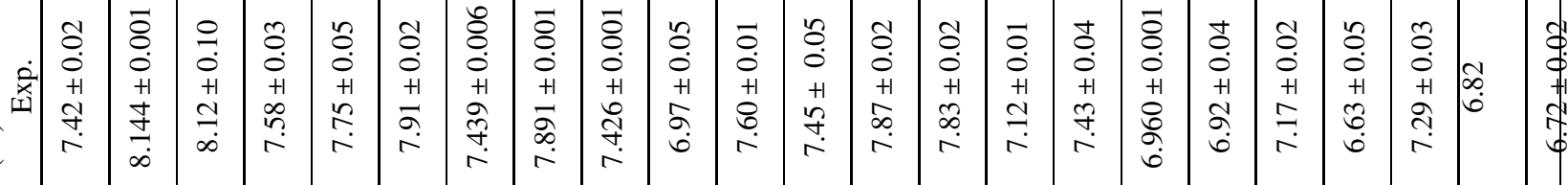

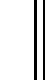




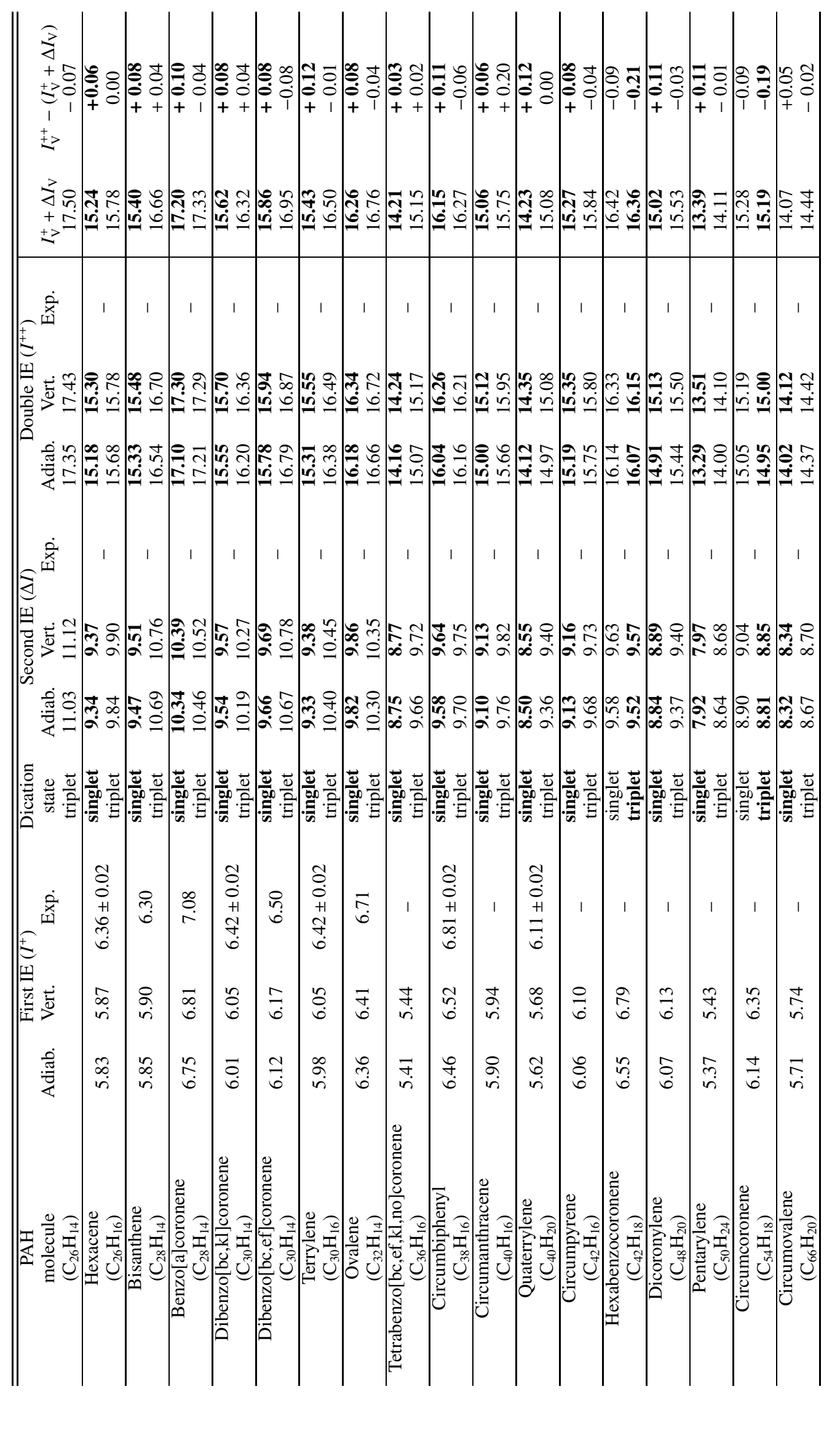

